\title{
Evaluation of immunotherapy and targeted therapy treatment on renal cell carcinoma: A Bayesian network analysis
}

\author{
WEI WEI, RUIHAO PENG, LISHAN KUANG, CHANGYUAN XU, YAN CAO, LUQING ZENG, \\ XIMEI WEN, QIANQIAN QIN, CUNCAI ZHENG, WENYUN LI and SUJIAN XIA \\ Department of Health Statistics, School of Medicine, Jinan University, Guangzhou, Guangdong 510632, P.R. China
}

Received February 28, 2019; Accepted October 10, 2019

DOI: $10.3892 / 01.2019 .11094$

\begin{abstract}
Clinical trials have previously assessed various therapies for renal cell carcinoma (RCC); however, there is currently a lack of direct comparisons between these therapies. The present study identified published studies on RCC through Web of Science, PubMed, EMBASE, Cochrane Library of Controlled Trials and Clinical trials.gov that were written in the English language and published by February 2019. The data were selected and extracted independently by two reviewers. Standard pair-wise meta-analyses were performed using Stata. Network meta-analyses were subsequently performed using WinBUGS (version 1.4.3). The primary outcome of the present study was progression-free survival (PFS). Secondary outcomes included overall survival (OS), objective response rate (ORR) and adverse events of various targeted therapies. The results were presented as cumulative odds ratio, hazard ratio, corresponding $95 \%$ confidence interval and the surface under the cumulative ranking curve, which was used to rank the probabilities and outcome of each treatment in RCC. A total of 31 eligible publications for 18 randomized controlled trials consisting of 11,498 participants were included in the present study. The network meta-analyses revealed that a combination of lenvantinib and everolimus ranked first out of 16 treatments in terms of PFS, OS and ORR (probability of $54.0,53.4$ and $61.0 \%$, respectively).
\end{abstract}

\section{Introduction}

Renal cell carcinoma (RCC) is a malignant tumor that originates in the renal pituitary epithelial system and has the second highest incidence rate of genitourinary tumors (1). In the United States of America in 2018, RCC had the eighth highest incidence rate among adult tumors, with 65,340 new cases

Correspondence to: Dr Sujian Xia, Department of Health Statistics, School of Medicine, Jinan University, 601 Huangpudadao Road, Guangzhou, Guangdong 510632, P.R. China

E-mail: xiasujian@126.com

Key words: Bayes' theorem, carcinoma, renal cell, human kidney neoplasms diagnosed (1). According to the American Cancer Society, RCC had the highest mortality rate with 14,240 mortalities in 2018 (1). Approximately one-third of patients with RCC had metastases prior to their first hospital visit, and exhibited a high recurrence rate and poor prognosis in the later stage of disease (2). Even with early detection and early radical resection, $20-40 \%$ of patients experience distant metastasis or recurrence (3). The 5-year overall survival (OS) time of patients with metastatic RCC (mRCC) is <10\% (4). RCC is not sensitive to traditional radiotherapy and chemotherapy, including cytotoxic chemotherapy, 5-fluorouracil- and floxuridin (FUDR)-based chemotherapy (5), and radical or partial nephrectomy is currently the primary method of treatment for RCC (6). Targeted therapy is the most effective treatment for $\operatorname{mRCC}(7)$.

Retrospective analysis revealed that, prior to 2005, high-dose interleukin 2 (IL-2) or interferon $\alpha$ (IFN- $\alpha$ ) were the first-line drugs for the clinical management of RCC (8). Randomized phase III clinical trials demonstrated that temsirolimus, sunitinib and bevacizumab had clinical benefit compared with IFN- $\alpha$ for patients with RCC in terms of OS and progression free survival (PFS). Tesirolimus is a selective inhibitor of mammalian target of rapamycin (mTOR), a key component of the intracellular signaling transduction cascade that mediates cell proliferation and tumor angiogenesis. Tesirolimus synergistically binds to $12-\mathrm{kDa}$ FK506-binding protein (FKBP-12) to form a complex that inhibits mTOR kinase activity. This inhibition impairs translation of key regulatory proteins in the cell cycle, ultimately leading to G1/S arrest (9). Sunitinib is an oral tyrosine kinase inhibitor (TKI), targeting vascular endothelial growth factor (VEGF) (10). This receptor tyrosine kinase plays a key role in the pathogenesis of clear-cell carcinoma, the predominant type of renal-cell carcinoma, through involvement of the von Hippel-Lindau (VHL) gene. VHL is inactivated by deletion, mutation or methylation in up to $80 \%$ of sporadic cases of clear-cell carcinoma (11). VHL is a tumor-suppressor gene that encodes a protein involved in the regulation of the production of VEGF and a number of other hypoxia-inducible proteins. Inactivation of the VHL gene upregulates the VEGF receptor (VEGFR), and the resulting persistent stimulation of which may promote tumor angiogenesis and growth and metastasis (12). Bevacizumab and sunitinib bind to circulating VEGF, which produces a significant 
prolongation of time to disease progression in patients with metastatic RCC (13). In addition to temsirolimus, sunitinib and bevacizumab, sorafenib, pazopanib, everolimus, axitinib, cabozantinib, lenvantinib, dovitinib and nivolumab have been used for clinical trials for the treatment of RCC over the past two decades (14-44). Sunitinib, sorafenib, pazopanib, axitinib, cabozantinib, lenvantinib and dovitinib are TKIs that inhibit a number of receptors, including platelet derived growth factor receptor, Fms-like tyrosine kinase-3, fibroblast growth factor receptor, stem-cell growth factor and VEGFR $(10,21,23,24,32,45,46)$. Nivolumab is a humanized immunoglobulin monoclonal antibody that binds to programmed cell death 1 (PD-1) on activated immune cells and blocks binding of this receptor to its ligands PD-L1 and 2 , thereby eliminating the inhibition of immunosuppressive signal and enhancing the host's anti-tumor response (25). The development of targeted molecular therapies against VEGFR, PD-1 and mTOR has made the selection of the optimal treatment for patients challenging. However, mechanistically, agents that target PD-L1 or PD-1 are forms of immunotherapy and are distinct from targeted therapies.

There is currently a lack of direct comparison of the drugs used to treat RCC in clinical trials. Network meta-analysis is a novel technique that combines direct and indirect evidence, and provides useful comparisons between the different therapies (47). Furthermore, the results of different interventions for the treatment of similar diseases may be aggregated and quantitatively analyzed synthesized. The outcomes of the interventions are subsequently ranked, allowing the selection of the optimal treatment (48). The aim of the present study was to evaluate and compare the effectiveness and safety of various targeted therapies for RCC using a network meta-analysis.

\section{Materials and methods}

Inclusion and exclusion criteria. The present study followed the Preferred Reporting Items for Systematic Reviews and Meta-Analyses (PRISMA) extension statement for network meta-analyses(49).Priortoperforming thenetworkmeta-analysis, a protocol was published on PROSPERO (www.crd.york.ac.uk/ PROSPERO/display_record.php?ID=CRD42018086692) (50). Randomized control trials investigating temsirolimus, sunitinib, bevacizumab, sorafenib, pazopanib, everolimus, axitinib, cabozantinib, lenvantinib, dovitinib and nivolumab as monotherapy or combination therapy for the treatment of patients with RCC were included in the present study, irrespective of whether the patients had received any systemic therapy, including first-line sunitinib and cytokine-containing regimen. Studies for which full text was unavailable and participants in crossover populations were excluded, and parallel group trials allocate each participant to a single intervention for comparison with one or more alternative interventions. By contrast, crossover trials allocate each participant to a sequence of interventions. It is difficult to extract suitable data from a trial allowing crossover, and the carry-over (a type of period-by-intervention interaction) effects the assessment (51). Additionally, studies with treatment strategies that were not compared with other drugs or which lacked data on the primary outcomes investigated in the current study were excluded.
Search strategy. The Web of Science (apps.webofknowledge. com), PubMed (https://www.ncbi.nlm.nih.gov/pubmed), EMBASE (https://www.embase.com), Cochrane Library of Controlled Trials (https://www.cochranelibrary.com) and Clinical trials.gov (https://clinicaltrials.gov) were all searched for relevant publications published in the English language from inception to February 2019. Conference or seminal articles were also searched. A comprehensive search strategy was utilized, included the following terms: 'Renal cell carcinoma', 'temsirolimus', 'sunitinib', 'bevacizumab', 'sorafenib', 'pazopanib', 'everolimus', 'axitinib', 'cabozantinib', 'lenvantinib', 'dovitinib', 'nivolumab' and 'randomized controlled trial'. The full search strategy is available in the aforementioned published protocol (50).

Study selection and data collection. The reference management software EndNote (version X7) (52) was used to identify and remove duplicate records. The abstract and title of each publication were scanned independently by two reviewers to exclude studies that did not meet the inclusion criteria, and if required, full articles were assessed according to the PRISMA statement (53). If discrepancies arose, another reviewer participated in this process. The following data were extracted from the selected articles: Date of publication, first author, trial ID, trial phase, number of participants, drug used and patient outcome data. In the data extracting stage, the present study aimed to contact authors in order to obtain more information, but they were unavailable. Stata (version 13) (54) was used to draw a network plot to present the cumulative number of trials for each comparison and the number of enrolled participants, and to decide which trials to exclude according to the aforementioned exclusion criteria.

Outcome measures. The primary outcome of the present study was PFS, defined as the time from randomization to the first documentation of objective disease progression, or to mortality from any cause. Objective disease progression indicated a minimum $20 \%$ increase in the sum of diameters of target lesions, taking as reference the smallest value in the study, including the baseline, and an absolute increase of at least $5 \mathrm{~mm}$, appearance of one or more new target or non-target lesions, or unequivocal progression of existing non-target lesions. Secondary outcomes included OS, which was defined as the time from randomization to the date of death; objective response rate (ORR; assessed according to the Response Evaluation Criteria in Solid Tumors) (55) and safety (graded according to the Common Terminology Criteria for Adverse Events) (56).

Statistical analysis. The data analysis combined direct and indirect meta-analyses. A traditional pair-wise meta-analysis was performed to compare the same interventions. The fixed effects model was used to analyze data if the $\chi^{2}$ test and $\mathrm{I}^{2}$ index for testing heterogeneity among the study revealed that there was no statistically significant heterogeneity $(\mathrm{P}>0.1$; $\mathrm{I}^{2} \leq 25 \%$ ). Otherwise, a random effects model was used.

Network meta-analyses were conducted using the Bayesian Markov Chain Monte Carlo model with WinBUGS (version 14) (57). Each model was run for 40,000 burn-in simulations and 200,000 runs, which were then thinned every 20th simulation to decrease autocorrelation. The 


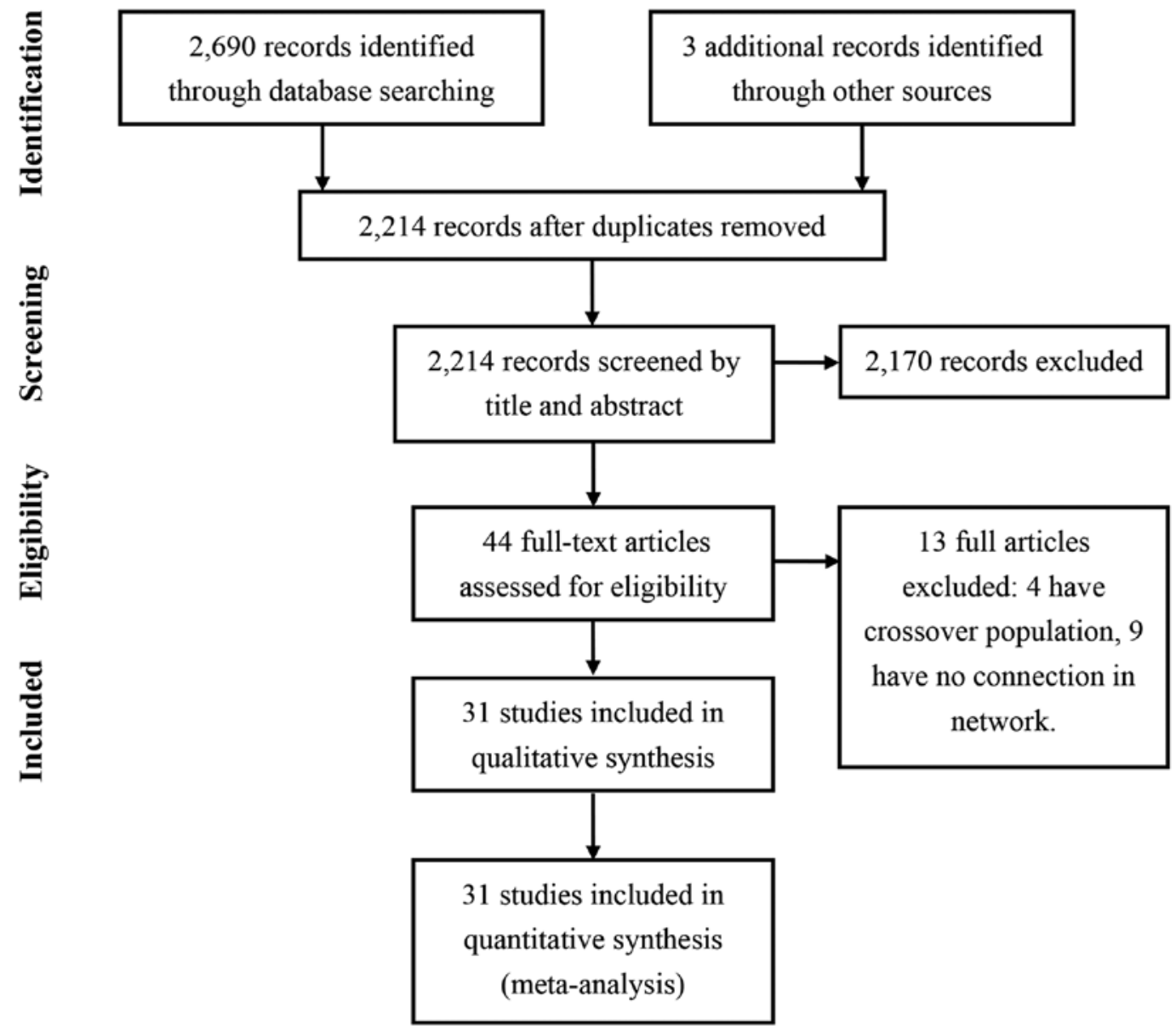

Figure 1. Flow chart of the study selection process. After study selection, 31 studies were included in the network meta-analysis.

mean log hazard ratio (HR) and standard error for each treatment were extracted to compare PFS and OS (58). The total number of events was used to compare ORR and safety. By comparing the deviance information criterion (DIC) value of fixed and random effect model, the model with lowest DIC was selected, or alternatively, the fixed effect model was selected when the discrepancy was <10 (59). If direct and indirect evidence was available, consistency was checked via model extensions to estimate the validation of mixed treatment comparison.

The probability of an intervention being the optimal intervention was calculated using rank code in WinBUGS and the surface under the cumulative ranking curve (SUCRA) values of all treatments were compared for efficacy and safety. Node-splitting analyses were used to assess inconsistencies in the network meta-analysis, which assessed whether direct and indirect evidence on a specific node (the split node) were in agreement.

\section{Results}

Study characteristics. The present study identified 2,693 potentially relevant publications. After excluding 479 duplications and 2,170 reports that did not meet the eligibility criteria (Fig. 1), 44 full articles were assessed for eligibility. A further 13 studies were excluded due to the following reasons: Having no connection to other treatments or were not the focus of the present study (including studies on the comparison of sorafenib, IFN- $\alpha 2$, combination of bevacizumab and IFN- $\alpha 2$ and the combination of erlotinib and bevacizumab), allocating each participant to a sequence of interventions, which may result in low quality conclusion and influence the result of the network meta-analysis. Overall, 31 publications covering 18 trials between 2007 and 2018 were included in the comparison meta-analysis of the present study (Table SI) (14-44). The 11,498 participants were randomly assigned to 16 treatment groups (including placebo, nivolumab, everolimus, lenvantinib plus everolimus, lenvantinib, cabozantinib, sunitinib, IFN $\alpha$, sorafenib, axitinib, temsirolimus, pazopanib, dovitinib, bevacizumab plus IFN $\alpha$, temsirolimus plus IFN- $\alpha$, or temsirolimus plus bevacizumab) and were included in the multiple-treatments meta-analysis. The dashed lines in the network plot indicated all possible direct comparisons (Fig. 2). Due to the limited number of published trials, data on a number of possible direct comparisons were not available. The solid lines represented existing evidence that was available.

Efficacy. The result of standard pair-wise meta-analysis only revealed a significant difference in PFS (HR, 0.69; 95\% CI, 0.60-0.79; $\mathrm{P}<0.0001$ ) and ORR (odds ratio, 2.51; 95\% CI, 1.18-3.51) between axitinib and sorafenib. The HRs of PFS were pooled by the fixed effect model, as the DIC values of the fixed and random effect models were 3.868 and -4.528 , respectively. The results of the primary outcome are presented in Table I. In terms of PFS, except for IFN- $\alpha$ (HR, 1.30; 95\% CI, 0.97-1.90), 


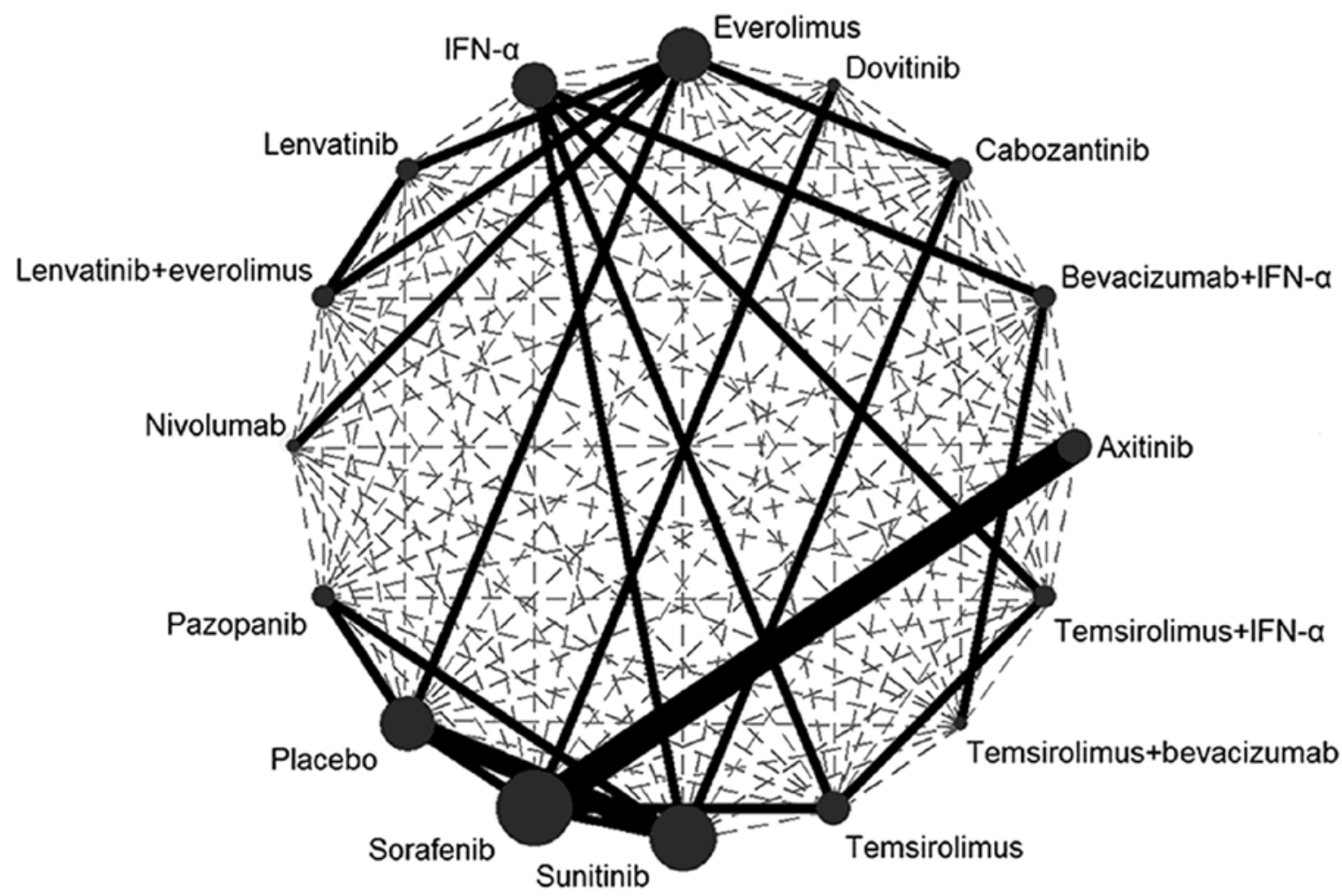

Figure 2. Networks of treatment comparisons for primary outcomes of 16 treatments in patients with RCC. Every node represents a treatment for RCC. The width of the lines represents the cumulative number of trials of each comparison and the size of every node is the proportional to the patient number of enrolled. RCC, renal cell carcinoma.

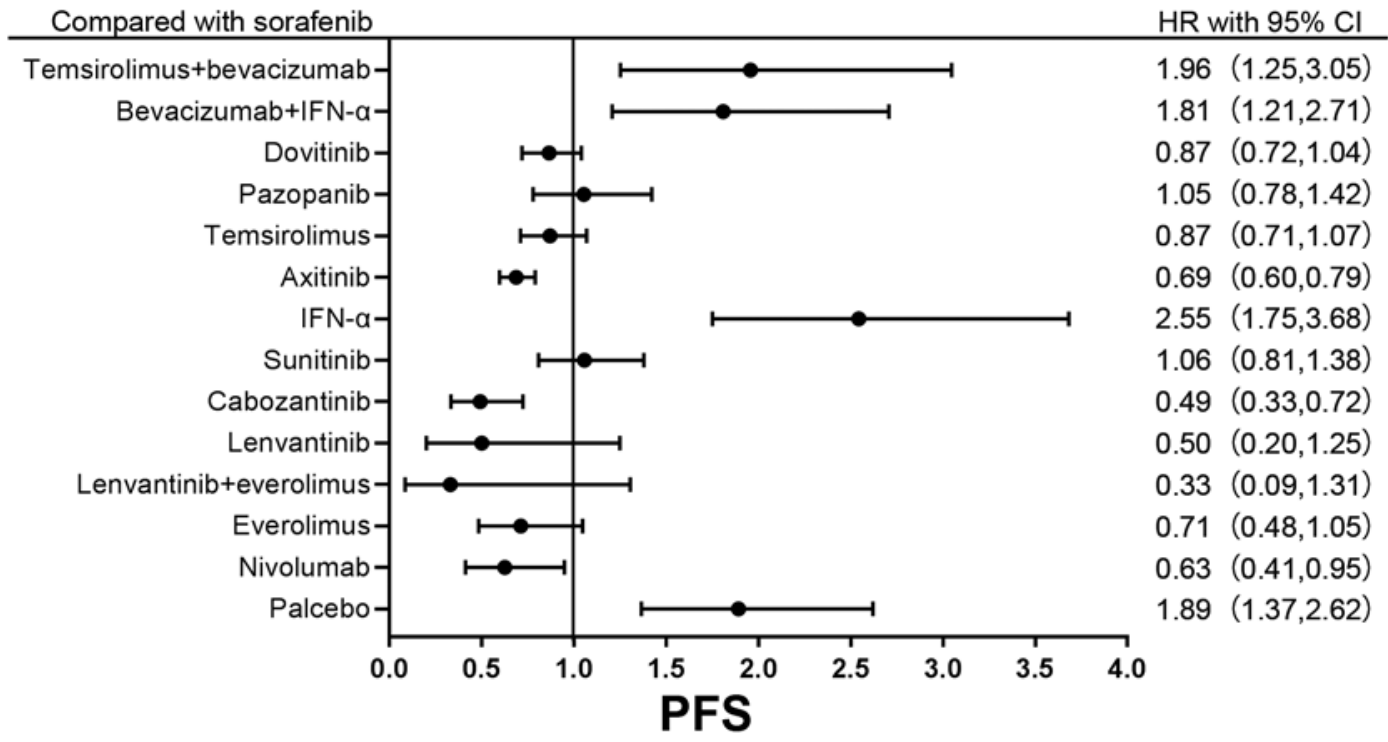

Figure 3. Forest plots representing the effect of targeted therapy on the PFS in renal cell carcinoma. Axitinib, cabozantinib, and nivolumab appeared to improve PFS. PFS, progression-free survival; IFN- $\alpha$, interferon $\alpha$; HR, hazard ratio; CI, confidence interval.

bevacizumab plus IFN- $\alpha$ (HR, 0.96; 95\% CI, 0.67-1.37) and bevacizumab plus temsirolimus (HR, 1.03; 95\% CI, 0.69-1.55), all treatments were significantly different from the placebo. Multiple comparisons of the HR of OS and the occurrence rate (OR) of ORR are presented in Tables SII and III. In addition, the forest plot comparing the primary outcomes between sorafenib and other drugs is presented in Fig. 3, as sorafenib was the first drug used as a targeted therapy in the treatment of RCC (60).
The probability of each treatment being ranked the highest in terms of survival, response and safety is presented in Fig. 4. The lenvantinib and everolimus combination ranked first out of the 16 treatments in terms of PFS, OS, ORR and OR of fatigue (probability of 54.0,53.4, 61.0 and 51.0\%, respectively). Lenvantinib monotherapy ranked first for nausea and second in the fatigue OR (probability of 61 and $25 \%$, respectively). Lenvantinib plus everolimus had the highest SUCRA value 


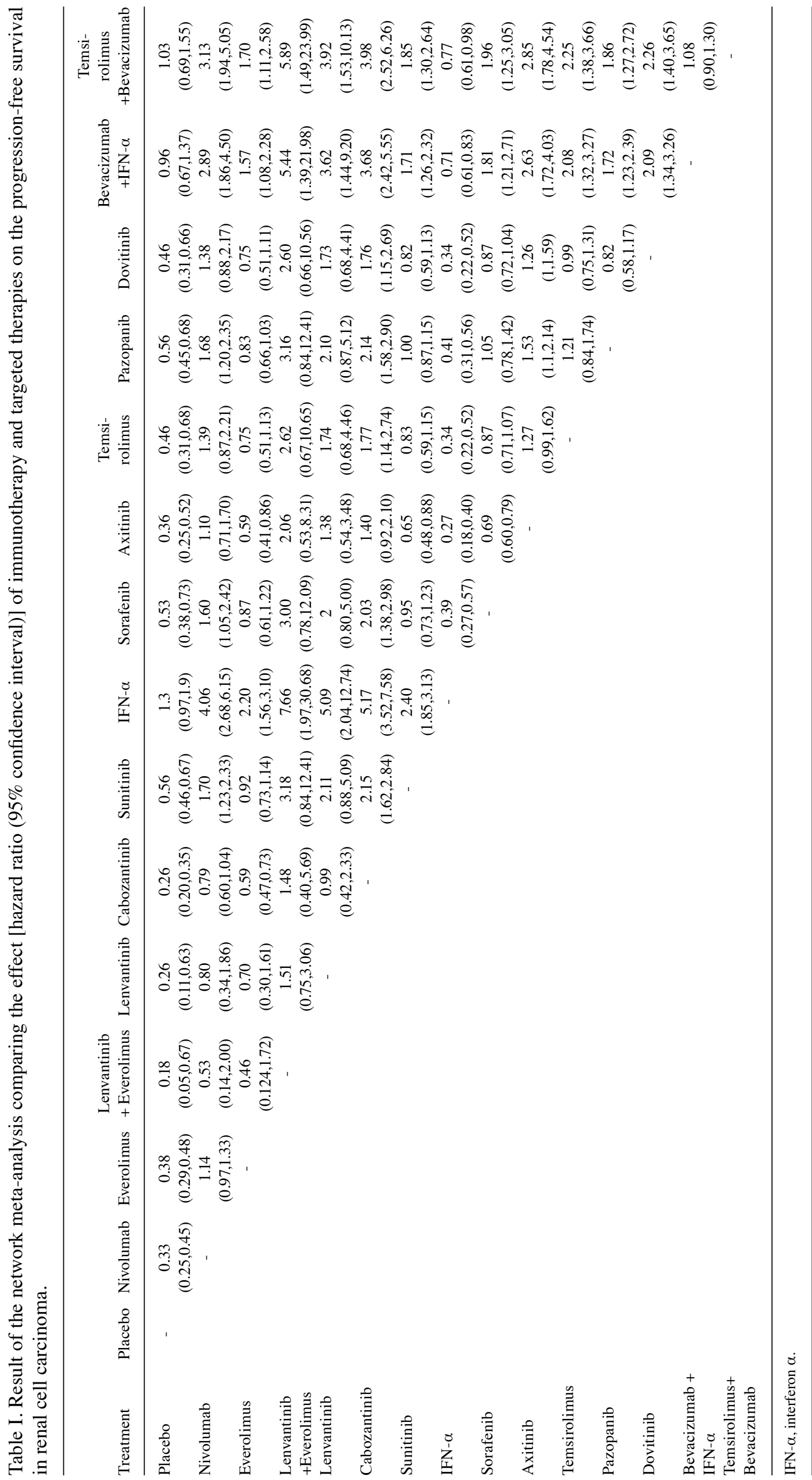


$\square$ PFS $\square$ OS $\square$ ORR $\backsim$ Fatigue 8 Nausea



Figure 4. The lenvantinib and everolimus combination ranked first out of the 16 treatments in terms of PFS, OS, ORR and occurrence rate of fatigue (probability of 54.0, 53.4, 61.0 and $51.0 \%$, respectively). IFN- $\alpha$, interferon $\alpha$; PFS, progression-free survival; OS, overall surviaval; ORR, objective response rate.


Figure 5. SUCRA curves of PFS. Each SUCRA curve represents the probability of every treatment ranking first based on the effect on PFS. The lenvantinib and everolimus combination ranked first out of the 16 treatments (probability of 92.3\%). SUCRA, surface under the cumulative ranking; PFS, progression-free survival; IFN- $\alpha$, interferon $\alpha$.

(92.3\%; Fig. 5). Consistency tests revealed there was no significant difference between the indirect and direct evidence $(\mathrm{P}>0.35)$. The forest plot for comparing PFS between TKIs and drugs targeting the same target is presented in Fig. 6. The result of network meta-analysis revealed no significant difference in PFS between TKIs and other drugs. 
Table II. Most common adverse events in each treatment group and their occurrence rate.

\begin{tabular}{|c|c|c|c|}
\hline Treatment & Most common adverse event & Any grade $(\%)$ & Grades 3 or $4(\%)$ \\
\hline Nivolumab & Fatigue & 33 & 2 \\
\hline \multirow{2}{*}{ Everolimus } & Fatigue & $20-46$ & $2-7$ \\
\hline & Stomatitis & $24-42$ & $2-4$ \\
\hline \multirow[t]{2}{*}{ Cabozantinib } & Fatigue & $56-85.9$ & $6.4-9$ \\
\hline & Diarrhea & $71-74$ & $10.3-11$ \\
\hline Lenvatinib+Everolimus & Diarrhoea & 85 & 20 \\
\hline \multirow[t]{2}{*}{ Lenvatinib } & Proteinuria & 31 & 19 \\
\hline & Diarrhoea & 72 & 12 \\
\hline \multirow[t]{3}{*}{ Sunitinib } & Fatigue & $13.6-81.9$ & $2-18$ \\
\hline & Hypertension & $6.4-68.1$ & $2-22$ \\
\hline & Diarrhea & $14.1-56.9$ & $1-11$ \\
\hline \multirow[t]{3}{*}{ Sorafenib } & Hand-foot syndrome & $39-56.5$ & $7.2-33$ \\
\hline & Diarrhoea & $30.4-63$ & $1.4-9$ \\
\hline & Hypertension & $28-36.3$ & $1-17$ \\
\hline \multirow[t]{2}{*}{ Axitinib } & Hypertension & $42-49.6$ & $14-19.3$ \\
\hline & Diarrhoea & $34.1-54$ & $3-11$ \\
\hline \multirow[t]{3}{*}{ Bevacizumab+IFN- $\alpha$} & Fatigue & - & 37 \\
\hline & Proteinuria & 27 & $13-15$ \\
\hline & Pyrexia & 39 & 3 \\
\hline IFN- $\alpha$ & Fatigue & 32 & $13-30$ \\
\hline \multirow[t]{3}{*}{ Temsirolimus } & Fatigue & $24.5-40$ & $5.3-6$ \\
\hline & Anemia & $21.6-34$ & $9-9.6$ \\
\hline & Rash & $22.6-42$ & $2-3$ \\
\hline \multirow{2}{*}{ Temsirolimus+IFN- $\alpha$} & Fatigue & 29.80 & 13.50 \\
\hline & Anemia & 29.30 & 18.30 \\
\hline Temsirolimus+Bevacizumab & Proteinuria & 36 & 16 \\
\hline \multirow[t]{3}{*}{ Pazopanib } & Fatigue & $19-55$ & $2-10$ \\
\hline & Diarrhea & 52 & 3 \\
\hline & Hypertension & 40 & 4 \\
\hline \multirow[t]{3}{*}{ Dovitinib } & Hypertriglyceridaemia & 20 & 14 \\
\hline & Fatigue & 41 & 10 \\
\hline & Diarrhea & 68 & 7 \\
\hline
\end{tabular}

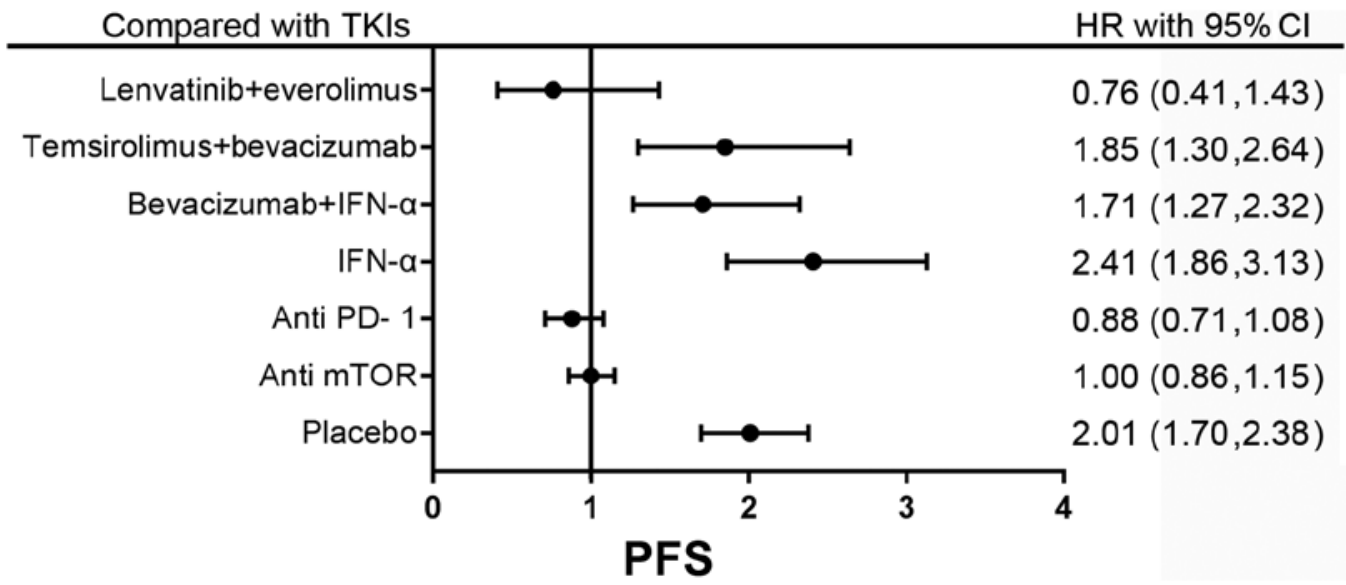

Figure 6. Comparison of progression-free survival between drugs acting on the same target. The result of network meta-analysis revealed no significant difference in PFS between TKIs and other drugs. PFS, progression-free survival; TKIs, tyrosine kinase inhibitors; IFN- $\alpha$, interferon $\alpha$; PD-1, programmed death 1; mTOR, mammalian target of rapamycin; HR, hazard ratio; CI, confidence interval.

Safety. Fatigue and nausea were considered as two important adverse events. Using a Bayesian meta-analysis it was observed that lenvantinib plus everolimus, cabozantinib and sunitinib had higher probability of fatigue (OR, 5.89; $95 \% \mathrm{CI}$, 1.07-33.90; and OR, 3.81, 95\% CI, 1.24-12.92; and OR 2.06;
95\% CI, 1.16-3.95, respectively) compared with the placebo, whereas the other drugs demonstrated no significant difference from the placebo and with each other. With the exception of pazopanib and sunitinib (OR, 3.34; 95\% CI, 1.12-11.02 and OR, 3.41; 95\% CI, 1.08-11.04, respectively), the drugs were 
not significantly different from placebo in the probability of nausea (Tables SIV and V). Notably, patients treated with lenvantinib were more susceptible to nausea compared with those treated with nivolumab or everolimus.

The results regarding drug safety from the probability analysis are presented in Fig. 4. Lenvantinib plus everolimus caused greater levels of fatigue than lenvantinib monotherapy or everolimus monotherapy. Patients receiving levantinib and eovitinib were more prone to experiencing nausea.

Due to insufficient data, other adverse events were not analyzed by the Bayesian meta-analysis, and the results regarding safety that were extracted from the included publications are summarized in Table II. Cabozantinib and lenvantinib plus everolimus had the highest rate of any grade of adverse events, and grade 3 or 4 adverse events most frequently occurred in the bevacizumab plus IFN- $\alpha$ treatment group.

\section{Discussion}

To the best of the authors' knowledge, the present network meta-analysis was the first to provide an indirect comparison of the efficacy and safety of all existing targeted therapies (temsirolimus, sunitinib, bevacizumab, sorafenib, pazopanib, everolimus, axitinib, cabozantinib, lenvantinib, dovitinib and nivolumab) for the treatment of RCC. The present study was based on 31 publications, which included 11,498 individuals randomly assigned to 16 different targeted therapies. As the primary analysis was reliant on the Bayesian Markov Chain Monte Carlo model, the HR of PFS for targeted therapies and the probability of each treatment being most effective was assessed, and it was revealed that lenvantinib plus everolimus was ranked first in terms of PFS, OS and ORR. Lenvantinib plus everolimus was also ranked first in terms of the occurrence of fatigue. Although not every comparison had a significant outcome, the treatments were still ranked. The results of the present study revealed that the use of lenvatinib plus everolimus, lenvatinib monotherapy, cabozantinib, nivolumab and everolimus significantly extended PFS. The use of lenvatinib plus everolimus, lenvatinib monotherapy, cabozantinib, sorafenib and axitinib significantly increased OS. The use of lenvatinib plus everolimus, lenvatinib monotherapy, nivolumab, cabozantinib and pazopanib significantly improved the ORR. Previous evidence had indicated that patients with a poor prognosis benefited from the use of cabozantinib in terms of survival, whereas the use of nivolumab exhibited a greater benefit for patients with a better prognosis (61). The present study demonstrated that there was no significant difference between nivolumab and cabozantinib use in PFS, OS and ORR. Inconsistencies arose when the two drugs were analyzed in one network, which was influenced by numerous factors, including the extent of heterogeneity in indirect comparison that was significantly associated with the inconsistency (62). The present analysis suggested that lenvantinib plus everolimus may be considered superior to other drugs. Axitinib and sorafenib differed significantly in both the network meta-analysis and pair-wise meta-analysis. This was consistent with the results of the direct comparison, in which axitinib was more beneficial than sorafenib.

The strength of the analysis in the present study rests on its transparent design. The analysis was conducted according to a predesigned and published protocol (50), and all predefined research questions were answered. A traditional standard meta-analysis is based on evidence from direct comparisons, the results from which may help to improve the health policy and reduce the risk of mortality, however it could not analyze more than two interventions at once or select the best option (47). In the present study, the therapies were ranked based on the Bayesian network meta-analysis. To the best of the authors' knowledge, there are currently limited published data comparing all available targeted drugs for RCC. A similar network meta-analysis published by He et al (63) in 2017 ranked single-drug targeted therapies in terms of response while Rousseau et al (64) assessed the efficacy of antiangiogenic agents for metastatic RCC. The present study focused on PFS and included an analysis of the combination of targeted therapies, which makes the present study relevant in the clinical setting and provides improved transitivity.

Although IFN- $\alpha$ does not belong to the targeted therapy or immunotherapy treatment types, it was still included in the network meta-analysis, as it is indispensable as a link between sunitinib, temsirolimus, temsirolimus plus IFN- $\alpha$ and bevacizumab plus IFN- $\alpha$. A total of 13 publications were excluded after reading the full-text as they may have influenced the transitivity of the results.

The present study revealed that a combination of lenvatinib plus everolimus was ranked first in terms of PFS, OS and ORR and that nivolumab may be used in patients with moderate disease, as this group exhibited fewer adverse events. Therefore, these results may aid in the selection of therapeutic drugs for patients with RCC.

\section{Acknowledgements}

Not applicable.

\section{Funding}

No funding was received.

\section{Availability of data and materials}

The datasets used and analyzed during the present study are available from the corresponding author upon reasonable request.

\section{Authors' contributions}

WW, RP, LK, CX, YC, LZ, XW, QQ, CZ, WL and SX participated in the design of the study. WW wrote the article, RP scanned and excluded studies, LK searched the database and extracted data, CX, YC LZ, XW, QQ and CZ searched the database and analyzed the data and WL checked the grammar and spelling. All authors read and approved the final manuscript.

\section{Ethics approval and consent to participate}

Not applicable.

\section{Patient consent for publication}

Not applicable. 


\section{Competing interests}

The authors declare that they have no competing interests.

\section{References}

1. Siegel RL, Miller KD and Jemal A: Cancer statistics, 2018. CA Cancer J Clin 68: 7-30, 2018

2. Brookman-May SD, May M, Shariat SF, Novara G, Zigeuner R, Cindolo L, De Cobelli O, De Nunzio C, Pahernik S, Wirth MP, et al: Time to recurrence is a significant predictor of cancer-specific survival after recurrence in patients with recurrent renal cell carcinoma-results from a comprehensive multi-centre database (CORONA/SATURN-Project). BJU Int 112: 909-916, 2013.

3. Tosco L, Van Poppel H, Frea B, Gregoraci G and Joniau S: Survival and impact of clinical prognostic factors in surgically treated metastatic renal cell carcinoma. Eur Urol 63: 646-652, 2013.

4. Garcia JA and Rini BI: Recent progress in the management of advanced renal cell carcinoma. CA Cancer J Clin 57: 112-125, 2007

5. Hartmann JT and Bokemeyer C: Chemotherapy for renal cell carcinoma. Anticancer Res 19: 1541-1543, 1999.

6. Motzer RJ and Russo P: Systemic therapy for renal cell carcinoma. J Urol 163: 408-417, 2000.

7. Gore ME and Larkin JM: Challenges and opportunities for converting renal cell carcinoma into a chronic disease with targeted therapies. Br J Cancer 104: 399-406, 2011.

8. Motzer RJ, Bacik J, Murphy BA, Russo P and Mazumdar M: Interferon-alfa as a comparative treatment for clinical trials of new therapies against advanced renal cell carcinoma. J Clin Oncol 20: 289-296, 2002.

9. Harding MW: Immunophilins, mTOR and Pharmacodynamic Strategies for a targeted cancer therapy. Clin Cancer Res 9: 2882-2886, 2003.

10. Mendel DB, Laird AD, Xin X, Louie SG, Christensen JG, Li G, Schreck RE, Abrams TJ, Ngai TJ, Lee LB, et al: In vivo antitumor activity of SU11248, a novel tyrosine kinase inhibitor targeting vascular endothelial growth factor and platelet-derived growth factor receptors: Determination of a pharmacokinetic/pharmacodynamic relationship. Clin Cancer Res 9: 327-337, 2003.

11. Gnarra JR, Tory K, Weng Y, Schmidt L, Wei MH, Li H, Latif F, Liu S, Chen F, Duh FM, et al: Mutations of the VHL tumour suppressor gene in renal carcinoma. Nat Genet 7: 85-90, 1994.

12. Na XI, Wu G, Ryan CK, Schoen SR, di'Santagnese PA and Messing EM: Overproduction of vascular endothelial growth factor related to von Hippel-Lindau tumor suppressor gene mutations and hypoxia-inducible factor- 1 alpha expression in renal cell carcinomas. J Urol 170: 588-592, 2003.

13. Yang JC, Haworth L, Sherry RM, Hwu P, Schwartzentruber DJ, Topalian SL, Steinberg SM, Chen HX and Rosenberg SA: A Randomized trial of bevacizumab, an anti-vascular endothelial growth factor antibody, for metastatic renal cancer. N Engl J Med 349: 427-434, 2003.

14. Motzer RJ, Ravaud A, Patard JJ, Pandha HS, George DJ, Patel A, Chang YH, Escudier B, Donskov F, Magheli A, et al: Adjuvant Sunitinib for High-risk renal cell carcinoma after nephrectomy: Subgroup analyses and updated overall survival results. Eur Urol 73: 62-68, 2018.

15. Tomita Y, Fukasawa S, Shinohara N, Kitamura H, Oya M, Eto M, Tanabe K, Kimura G, Yonese J, Yao M, et al: Nivolumab versus everolimus in advanced renal cell carcinoma: Japanese subgroup analysis from the CheckMate 025 study. Jpn J Clin Oncol 47: 639-646, 2017

16. Hutson TE, Al-Shukri S, Stus VP, Lipatov ON, Shparyk Y, Bair AH, Rosbrook B, Andrews GI and Vogelzang NJ: Axitinib Versus Sorafenib in First-line metastatic renal cell carcinoma: Overall survival from a randomized phase III trial. Clin Genitourin Cancer 15: 72-76, 2017.

17. Choueiri TK, Halabi S, Sanford BL, Hahn O, Michaelson MD, Walsh MK, Feldman DR, Olencki T, Picus J, Small EJ, et al: Cabozantinib versus sunitinib as initial targeted therapy for patients with metastatic renal cell carcinoma of poor or intermediate risk: The alliance A031203 CABOSUN trial. J Clin Oncol 35: 591-597, 2017.

18. Ravaud A, Motzer RJ, Pandha HS, George DJ, Pantuck AJ, Patel A, Chang YH, Escudier B, Donskov F, Magheli A, et al: Adjuvant sunitinib in high-risk renal-cell carcinoma after nephrectomy. N Engl J Med 375: 2246-2254, 2016.
19. Motzer RJ, Hutson TE, Ren M, Dutcus C and Larkin J: Independent assessment of lenvatinib plus everolimus in patients with metastatic renal cell carcinoma. Lancet Oncol 17: e4-e5, 2016.

20. Haas NB, Manola J, Uzzo RG, Flaherty KT, Wood CG, Kane C, Jewett M, Dutcher JP, Atkins MB,Pins M, et al: Adjuvant sunitinib or sorafenib for high-risk, non-metastatic renal-cell carcinoma (ECOG-ACRIN E2805): A double-blind, placebo-controlled, randomised, phase 3 trial. Lancet 387: 2008-2016, 2016.

21. Choueiri TK, Escudier B, Powles T, Tannir NM, Mainwaring PN, Rini BI, Hammers HJ, Donskov F, Roth BJ, Peltola K, et al: Cabozantinib versus everolimus in advanced renal cell carcinoma (METEOR): Final results from a randomised, open-label, phase 3 trial. Lancet Oncol 17: 917-927, 2016.

22. Beaumont JL, Salsman JM, Diaz J, Deen KC, McCann L, Powles T, Hackshaw MD, Motzer RJ and Cella D: Quality-adjusted time without symptoms or toxicity analysis of pazopanib versus sunitinib in patients with renal cell carcinoma. Cancer 122: 1108-1115, 2016

23. Qin S, Bi F, Jin J, Cheng Y, Guo J, Ren X, Huang Y, Tarazi J, Tang J, Chen C, et al: Axitinib versus sorafenib as a second-line therapy in Asian patients with metastatic renal cell carcinoma: Results from a randomized registrational study. Onco Targets Ther 8: 1363-1373, 2015.

24. Motzer RJ, Hutson TE, Glen H, Michaelson MD, Molina A, Eisen T, Jassem J, Zolnierek J, Maroto JP, Mellado B, et al: Lenvatinib, everolimus and the combination in patients with metastatic renal cell carcinoma: A randomised, phase 2, open-label, multicentre trial. Lancet Oncol 16: 1473-1482, 2015.

25. Motzer RJ, Escudier B, McDermott DF, George S, Hammers HJ, Srinivas S, Tykodi SS, Sosman JA, Procopio G, Plimack ER, et al: Nivolumab versus everolimus in advanced renal-cell carcinoma. N Engl J Med 373: 1803-1813, 2015.

26. Choueiri TK, Escudier B, Powles T, Mainwaring PN, Rini BI, Donskov F, Hammers H, Hutson TE, Lee JL, Peltola K, et al: Cabozantinib versus Everolimus in advanced renal-cell carcinoma. N Engl J Med 373: 1814-1823, 2015.

27. Rini BI, Bellmunt J, Clancy J, Wang K, Niethammer AG, Hariharan S and Escudier B: Randomized phase III trial of temsirolimus and bevacizumab versus interferon alfa and bevacizumab in metastatic renal cell carcinoma: INTORACT trial. J Clin Oncol 32: 752-759, 2014.

28. Motzer RJ, Porta C, Vogelzang NJ, Sternberg CN, Szczylik C, Zolnierek J, Kollmannsberger C, Rha SY, Bjarnason GA, Melichar B, et al: Dovitinib versus sorafenib for third-line targeted treatment of patients with metastatic renal cell carcinoma: An open-label, randomised phase 3 trial. Lancet Oncol 15: 286-296, 2014

29. Hutson TE, Escudier B, Esteban E, Bjarnason GA, Lim HY, Pittman KB, Senico P, Niethammer A, Lu DR, Hariharan S and Motzer RJ: Randomized phase III trial of temsirolimus versus sorafenib as second-line therapy after sunitinib in patients with metastatic renal cell carcinoma. J Clin Oncol 32: 760-767, 2014.

30. Ueda T, Uemura H, Tomita Y, Tsukamoto T, Kanayama H, Shinohara N, Tarazi J, Chen C, Kim S, Ozono S, et al: Efficacy and safety of axitinib versus sorafenib in metastatic renal cell carcinoma: Subgroup analysis of Japanese patients from the global randomized Phase 3 AXIS trial. Jpn J Clin Oncol 43: 616-628, 2013.

31. Sternberg CN, Hawkins RE, Wagstaff J, Salman P, Mardiak J, Barrios CH, Zarba JJ, Gladkov OA, Lee E, Szczylik C, et al: A randomised, double-blind phase III study of pazopanib in patients with advanced and/or metastatic renal cell carcinoma: Final overall survival results and safety update. Eur J Cancer 49: 1287-1296, 2013

32. Motzer RJ, Hutson TE, Cella D, Reeves J, Hawkins R, Guo J, Nathan P, Staehler M, de Souza P, Merchan JR, et al: Pazopanib versus sunitinib in metastatic renal-cell carcinoma. N Engl J Med 369: 722-731, 2013.

33. Motzer RJ, Escudier B, Tomczak P, Hutson TE, Michaelson MD Negrier S, Oudard S, Gore ME, Tarazi J, Hariharan S, et al: Axitinib versus sorafenib as second-line treatment for advanced renal cell carcinoma: Overall survival analysis and updated results from a randomised phase 3 trial. Lancet Oncol 14: 552-562, 2013.

34. Hutson TE, Lesovoy V, Al-Shukri S, Stus VP, Lipatov ON, Bair AH, Rosbrook B, Chen C, Kim S and Vogelzang NJ: Axitinib versus sorafenib as first-line therapy in patients with metastatic renal-cell carcinoma: A randomised open-label phase 3 trial. Lancet Oncol 14: 1287-1294, 2013. 
35. Rini BI,Escudier B, Tomczak P, Kaprin A, Szczylik C, Hutson TE, Michaelson MD, Gorbunova VA, Gore ME, Rusakov IG, et al: Comparative effectiveness of axitinib versus sorafenib in advanced renal cell carcinoma (AXIS): A randomised phase 3 trial. Lancet 378: 1931-1939, 2011.

36. Sternberg CN, Davis ID, Mardiak J, Szczylik C, Lee E, Wagstaff J, Barrios CH, Salman P, Gladkov OA, Kavina A, et al: Pazopanib in locally advanced or metastatic renal cell carcinoma: Results of a randomized phase III trial. J Clin Oncol 28: 1061-1068, 2010.

37. Rini BI, Halabi S, Rosenberg JE, Stadler WM, Vaena DA, Archer L, Atkins JN, Picus J, Czaykowski P, Dutcher J and Small EJ: Phase III trial of bevacizumab plus interferon alfa versus interferon alfa monotherapy in patients with metastatic renal cell carcinoma: Final results of CALGB 90206. J Clin Oncol 28: 2137-2143, 2010.

38. Motzer RJ, Escudier B, Oudard S, Hutson TE, Porta C, Bracarda S, Grünwald V, Thompson JA, Figlin RA, Hollaender N, et al: Phase 3 trial of everolimus for metastatic renal cell carcinoma: Final results and analysis of prognostic factors. Cancer 116: 4256-4265, 2010.

39. Motzer RJ, Hutson TE, Tomczak P, Michaelson MD, Bukowski RM, Oudard S, Negrier S, Szczylik C, Pili R, Bjarnason GA, et al: Overall survival and updated results for sunitinib compared with interferon alfa in patients with metastatic renal cell carcinoma. J Clin Oncol 27: 3584-3590, 2009.

40. Dutcher JP, de Souza P, McDermott D, Figlin RA, Berkenblit A, Thiele A, Krygowski M, Strahs A, Feingold J and Hudes G: Effect of temsirolimus versus interferon-alpha on outcome of patients with advanced renal cell carcinoma of different tumor histologies. Med Oncol 26: 202-209, 2009.

41. Rini BI, Halabi S, Rosenberg JE, Stadler WM, Vaena DA, Ou SS Archer L, Atkins JN, Picus J, Czaykowski P, et al: Bevacizumab plus interferon alfa compared with interferon alfa monotherapy in patients with metastatic renal cell carcinoma: CALGB 90206. J Clin Oncol 26: 5422-5428, 2008

42. Motzer RJ, Escudier B, Oudard S, Hutson TE, Porta C, Bracarda S Grünwald V, Thompson JA, Figlin RA, Hollaender N, et al: Efficacy of everolimus in advanced renal cell carcinoma: A double-blind, randomised, placebo-controlled phase III trial. Lancet 372: 449-456, 2008

43. Motzer RJ, Hutson TE, Tomczak P, Michaelson MD Bukowski RM, Rixe O, Oudard S, Negrier S, Szczylik C, $\mathrm{Kim}$ ST, et al: Sunitinib versus interferon alfa in metastatic renal-cell carcinoma. N Engl J Med 356: 115-124, 2007.

44. Hudes G, Carducci M, Tomczak P, Dutcher J, Figlin R, Kapoor A, Staroslawska E, Sosman J, McDermott D, Bodrogi I, et al Temsirolimus, interferon alfa, or both for advanced renal-cell carcinoma. N Engl J Med 356: 2271-2281, 2007.

45. Lee SH, Lopes de Menezes D, Vora J, Harris A, Ye H, Nordahl L, Garrett E, Samara E, Aukerman SL, Gelb AB and Heise C: In vivo target modulation and biological activity of CHIR-258, a multitargeted growth factor receptor kinase inhibitor, in colon cancer models. Clin Cancer Res 11: 3633-3641, 2005.

46. Wilhelm SM, Carter C, Tang L, Wilkie D, McNabola A, Rong H, Chen C, Zhang X, Vincent P, McHugh M, et al: BAY 43-9006 exhibits broad spectrum oral antitumor activity and targets the RAF/MEK/ERK pathway and receptor tyrosine kinases involved in tumor progression and angiogenesis. Cancer Res 64: 7099-7109, 2004.

47. Tonin FS, Rotta I, Mendes AM and Pontarolo R: Network meta-analysis: A technique to gather evidence from direct and indirect comparisons. Pharm Pract (Granada) 15: 943, 2017.

48. Salanti G, Ades AE and Ioannidis JP: Graphical methods and numerical summaries for presenting results from multiple-treatment meta-analysis: An overview and tutorial J Clin Epidemiol 64: 163-171, 2011.

49. Hutton B, Salanti G, Caldwell DM, Chaimani A, Schmid CH, Cameron C, Ioannidis JP, Straus S, Thorlund K, Jansen JP, et al: The PRISMA extension statement for reporting of systematic reviews incorporating network meta-analyses of health care interventions: Checklist and explanations. Ann Intern Med 162: 777-784, 2015.
50. Wei W, Peng R, Zeng L, Xu C, Cao Y, Chen W and Xia S: Comparative efficacy and safety of targeted therapy in the treatment of renal cell carcinoma: A Bayesian network analysis. Value Health 21 (Suppl 2): S113, 2018.

51. Higgins JPT and Green S, (eds): Cochrane handbook for systematic reviews of interventions 4.2.6. The Cochrane Library 4 157-161, 2006.

52. Bramer WM, Giustini D, de Jonge GB, Holland L and Bekhuis T: De-duplication of database search results for systematic reviews in EndNote. J Med Libr Assoc 104: 240-243, 2016.

53. Moher D, Liberati A, Tetzlaff $\mathrm{J}$ and Altman DG; PRISMA Group: Preferred reporting items for systematic reviews and meta-analyses: The PRISMA statement. Int J Surg 8: 336-341, 2010.

54. Chaimani A, Higgins JP, Mavridis D, Spyridonos $P$ and Salanti G: Graphical tools for network meta-analysis in STATA. PLoS One 8: e76654, 2013.

55. Therasse P, Arbuck SG, Eisenhauer EA, Wanders J, Kaplan RS, Rubinstein L, Verweij J, Van Glabbeke M, van Oosterom AT, Christian MC and Gwyther SG: New guidelines to evaluate the response to treatment in solid tumors. European Organization for Research and Treatment of Cancer, National Cancer Institute of the United States, National Cancer Institute of Canada. J Natl Cancer Inst 92: 205-216, 2000

56. Trotti A, Colevas AD, Setser A, Rusch V, Jaques D, Budach V, Langer C, Murphy B, Cumberlin R, Coleman CN and Rubin P: CTCAE v3.0: Development of a comprehensive grading system for the adverse effects of cancer treatment. Semin Radiat Oncol 13: 176-181, 2003.

57. Lunn DJ, Thomas A, Best N and Spiegelhalter D: WinBUGS-A Bayesian modelling framework: Concepts, structure and extensibility. Stat Computing 10: 325-337, 2000.

58. Woods BS, Hawkins N and Scott DA: Network meta-analysis on the log-hazard scale, combining count and hazard ratio statistics accounting for multi-arm trials: A tutorial. BMC Med Res Methodol 10: 54, 2010.

59. Spiegelhalter DJ, Best NG, Carlin BP and Van Der Linde A: Bayesian measures of model complexity and fit. J Royal Stat Soc Series B (Statistical Methodology) 64: 583-639, 2002.

60. Kane RC, Farrell AT, Saber H, Tang S, Williams G, Jee JM, Liang C, Booth B, Chidambaram N, Morse D, et al: Sorafenib for the treatment of advanced renal cell carcinoma. Clin Cancer Res 12: 7271-7278, 2006.

61. Wiecek W and Karcher H: Nivolumab versus cabozantinib: Comparing overall survival in metastatic renal cell carcinoma. PLoS One 11: e0155389, 2016.

62. Song F, Xiong T, Parekh-Bhurke S, Loke YK, Sutton AJ, Eastwood AJ, Holland R, Chen YF, Glenny AM, Deeks JJ and Altman DG: Inconsistency between direct and indirect comparisons of competing interventions: Meta-epidemiological study. BMJ 343: d4909, 2011.

63. He HL and Yao WX: A network meta-analysis of short-term efficacy of different single-drug targeted therapies in the treatment of renal cell carcinoma. Biosci Rep 37: pii: BSR20170827, 2017.

64. Rousseau B, Kempf E, Desamericq G, Boissier E, Chaubet-Houdu M, Joly C, Saldana C, Boussion H, Neuzillet C, Macquin-Mavier I, et al: First-line antiangiogenics for metastatic renal cell carcinoma: A systematic review and network meta-analysis. Crit Rev Oncol Hematol 107: 44-53, 2016.

This work is licensed under a Creative Commons Attribution-NonCommercial-NoDerivatives 4.0 International (CC BY-NC-ND 4.0) License. 